\title{
The Dynamic Response of Etnean Sand and the Effect of Its Impingement on Ti-6Al-4 V Alloy
}

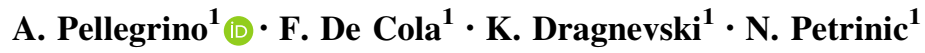

Received: 1 August 2016/Accepted: 17 September 2016/Published online: 3 October 2016

(C) Society for Experimental Mechanics, Inc 2016

\begin{abstract}
Quasi static and dynamic experiments were conducted to characterise the mechanical response of Etnean volcanic sand. Stress and strain histories were measured in near-uniaxial strain and near-uniaxial stress conditions at strain rates ranging between $5 \cdot 10^{-4}$ and $1.5 \cdot 10^{3} \mathrm{~s}^{-1}$ using bespoke experimental setups. The effects of the lateral confinement and initial consolidation state were assessed. Etnean volcanic sand exhibited a noticeable strain rate dependent behaviour when characterised in its loose consolidation state but not when densely packed before loading. The effect of volcanic particles impingement on Ti-6Al-4 $\mathrm{V}$ alloy was assessed by conducting dynamic experiments at different incident angles using targets of different geometry. The texture of thus eroded surfaces was analyzed by means of non-contact 3D-profilometry. The surface analysis provided insights on the erosion mechanisms and quantitative data on the roughness increment caused by the collision and rubbing with volcanic sand.
\end{abstract}

Keywords Granular materials · High strain rate ·

Hopkinson bar - Abrasion - Wear

\section{Introduction}

Volcanic sand is a granular material generated from the interaction between magma, water and air during volcanic explosions. Once the magmatic material reaches the Earth

A. Pellegrino

antonio.pellegrino@eng.ox.ac.uk

1 Department of Engineering Science, University of Oxford, Oxford OX1 3PJ, UK surface, it is subjected to rapid cooling accompanied by an increase of viscosity and reduction of fluidity caused by the emission of gases and vapour. Because of its viscosity and the fast cooling, the minerals present in the magmatic material cannot arrange themselves in an organized structure thus producing partially or completely vitreous rocks, shards and beads.

Etnean Volcanic ashes are mainly composed of two minerals: cristobalite and anorthite. The former is characterized by the same chemical composition of silica $\left(\mathrm{SiO}_{2}\right)$ but has a distinct crystalline structure, while the latter $\left(\mathrm{CaAl}_{2} \mathrm{Si}_{2} \mathrm{O}_{8}\right)$ is omnipresent in all rocks of Mount Etna [1-3].

The presence of volcanic sand in many engineering fields poses the need for a detailed characterisation of its mechanical behaviour. Hydrocarbons can be found in volcanic rock, sometimes in significant quantities [4]. However magmatic materials are very tough at the granular level, which is the level involved for example in drilling [5]. Therefore, the knowledge of the mechanical properties of volcanic sand provides information on the percussive and rotary drillability of igneous materials and on the consequent wear and tear of drilling tools $[6,7]$.

The mechanical response of volcanic ashes to impact loading is also of great interest to defense and quarrying industries [8], as granular materials exhibit considerable energy dissipation when subjected to blast loading and projectile penetration [9-11]. A compendium of experimental and numerical techniques for the study of rapid projectile penetration into granular media was recently presented by Iskander et al. in [12].

Additionally ash clouds from eruptions are regarded by international aviation agencies as a dangerous environment for aircraft engines and an immediate safety concern $[13,14]$. The abrasiveness of sands varies depending on 
particle size, shape, angularity and friability of the grains $[15,16]$. Volcanic sand is about four times more erosive then quartz sand [17]. The ingestion of volcanic particulate affects the performance, reliability and durability of gas turbine engines. Its impingement and deposition on blades

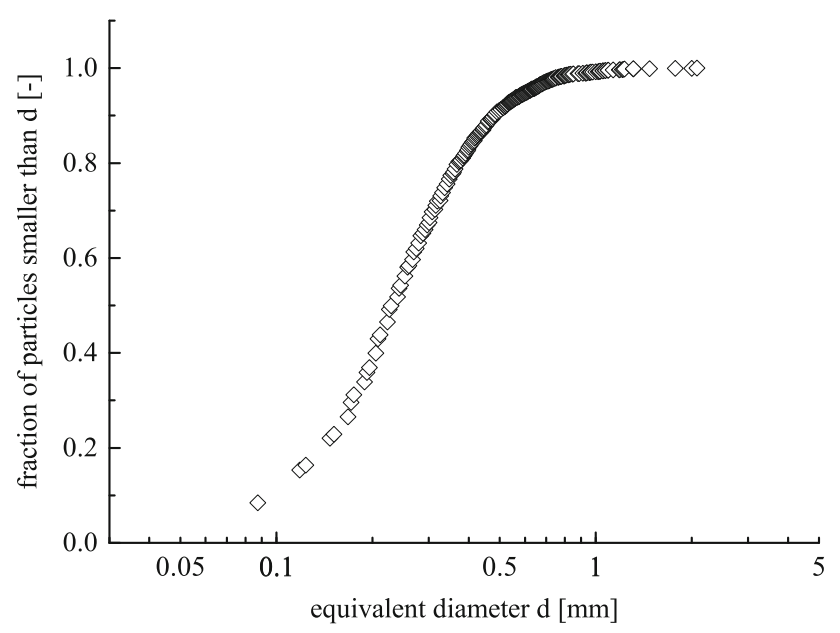

Fig. 1 Grain size distribution of the Etnean volcanic ashes utilised during the experiments
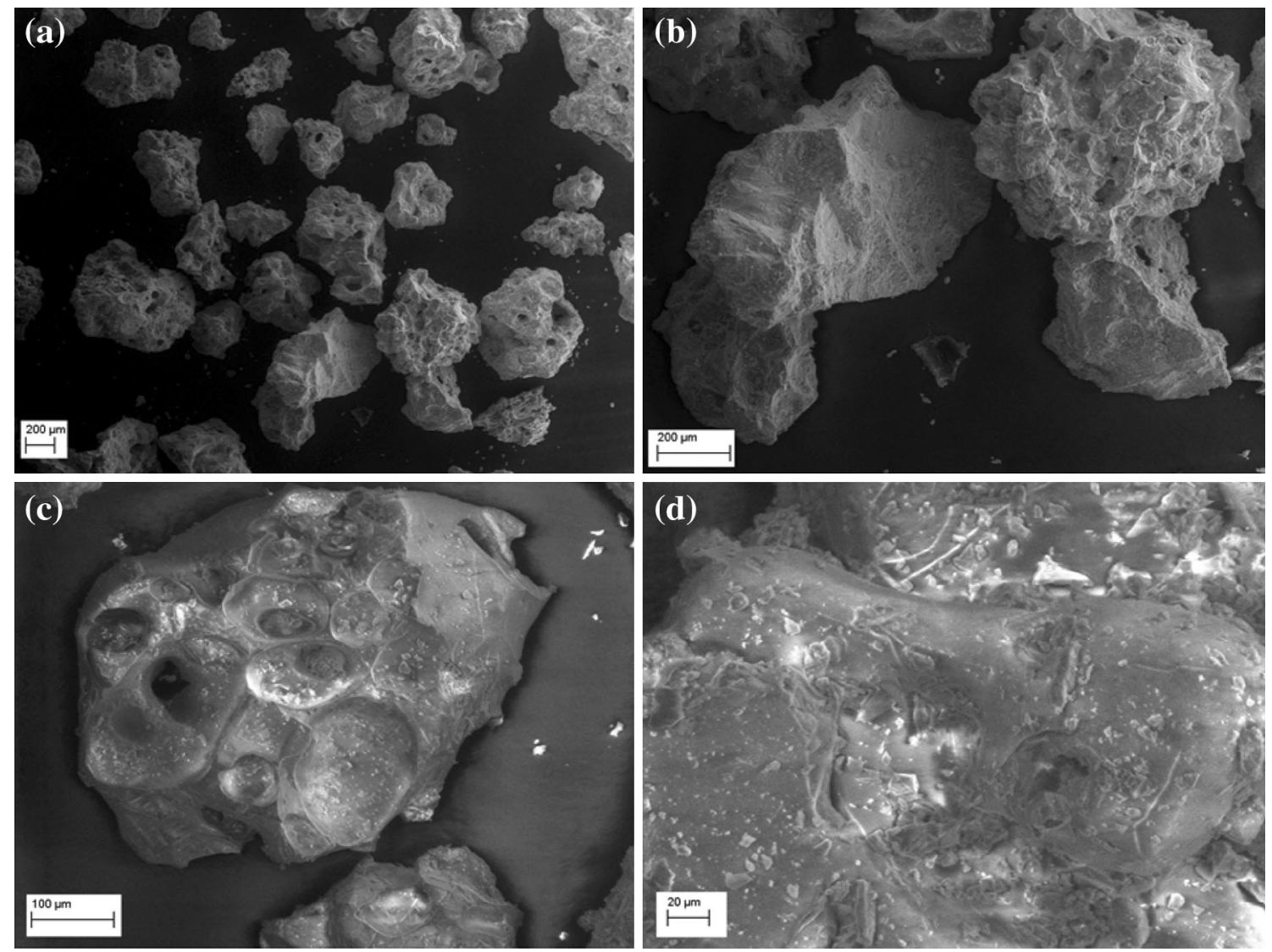

Fig. 2 ESEM images illustrating the morphology (a) and microstructure (b, c, d) of Etnean volcanic sand grains. The microstructure of Etnean volcanic ashes is characterised by the presence of numerous vesicles $(\mathbf{b}, \mathbf{c})$ and by a partially vitreous nature $(\mathbf{d})$ and vanes cause, among other effects, the erosion of stator and rotors surfaces thus modifying their profiles. This causes a loss in power, reduction of engine efficiency and its operating life $[18,19]$.

Etnean sand and rocks are also widely used as construction materials $[20,21]$. Furthermore a reliable characterization of the mechanical behavior of volcanic rock and sand is paramount for the interpretation of large-scale geophysical deformation data [22].

Previous studies have investigated the effect of strain rate and moisture content on the mechanical behaviour of granular materials [23, 24]. An empirical non-linear model based on the concept of strain energy density was used by SuescunFlorez et al. [25] to predict the compressive response of granular media over a wide range of strain rates. However none of the previous literature specifically investigated the rate dependent behaviour of volcanic sand and the effect of its impact and abrasion on Ti-6Al-4 V alloy.

To address the above described subjects an experimental campaign was undertaken in order to characterize the response of Etnean volcanic sand at two distinct, quasi static and high, rates of strain. The volcanic sand was collected from the South-East flank of the volcano during 
the paroxysm of the 28th of December 2014. The distribution of particle size was evaluated using contrast edge detection techniques and the microstructure of the volcanic sand grains was examined by means of Environmental Scanning Electron Microscopy.

Uniaxial compression tests were carried out by means of a screw-driven testing machine and a long split Hopkinson pressure bar (LSHPB) apparatus provided with a $2.7 \mathrm{~m}$ long striker. The dimensions of the granular material samples, correspondent to the minimum representative volume element, were defined to be an optimal compromise between minimizing the effects of the specimen's containment and achieving dynamic equilibrium during high strain rate compression tests [26].

During high rate compression experiments the load was transmitted from the input bar to the sample and from the sample to the output bar by means of two titanium alloy anvils. These were machined using the same material and the same cross section as the input and output bars of the apparatus to achieve perfect mechanical impedance matching. The anvils were replaced after every test and their surfaces, eroded by the impingement of volcanic particulate, were examined using tridimensional profilometry techniques. A series of additional tests was conducted using anvils of different geometries in order to evaluate the effect of the impact angle on the erosion mechanisms.

\section{Parent Material and Specimens Preparation}

The material under investigation was collected from the south east flank of Mount Etna following the explosive activity of the volcano in December 2014. The granular material was separated from impurities and sieved to obtain an approximately homogeneous size distribution of grains, representative of the average dimensions of the volcanic debris that reaches the neighbouring airport and cities during the eruptive activity. The distribution of particles size was evaluated using contrast edge detection techniques on binary images. A representative quantity of Etnean ashes, black in colour, was poured on a white surface and
Table 1 List of symbols

\begin{tabular}{|c|c|}
\hline$m_{d}$ & Mass of dense volcanic sand samples \\
\hline $\mathrm{m}_{1}$ & Mass of loose volcanic sand samples \\
\hline $\mathrm{m}_{\mathrm{w}}$ & Mass of the dropping weight using for compacting the dense volcanic sand samples \\
\hline 1 & Specimen length \\
\hline $\mathrm{d}$ & Specimen diameter \\
\hline$V_{v}$ & Volume of voids in volcanic sand samples \\
\hline$V_{s}$ & Volume of solids in volcanic sand samples \\
\hline$V_{t}$ & Total volume in volcanic sand samples \\
\hline$e=\frac{V_{v}}{V_{s}}$ & Void radio of volcanic sand samples \\
\hline$\eta=\frac{V_{v}}{V_{t}}$ & Porosity of volcanic sand samples \\
\hline$\varepsilon$ & Engineering strain \\
\hline$\dot{\varepsilon}$ & Engineering strain rate \\
\hline$\rho_{\mathrm{s}}$ & Density of Etnean volcanic sand grains $\left(2.86 \frac{\mathrm{g}}{\mathrm{cm}^{3}}\right)$ \\
\hline $\mathrm{F}_{\mathrm{i}}$ & Force at the interface between input bar and sand sample \\
\hline $\mathrm{F}_{\mathrm{o}}$ & Force at the interface between output bar and sand sample \\
\hline $\mathrm{R}_{\mathrm{a}}$ & Roughness average of titanium anvil roughness profile \\
\hline $\mathrm{R}_{\mathrm{q}}$ & Root mean square roughness of titanium anvil roughness profile \\
\hline $\mathrm{R}_{\mathrm{t}}$ & Maximum peak to valley height of roughness profile \\
\hline $1_{\mathrm{r}}$ & Length of the roughness profile examined \\
\hline $\mathrm{z}(\mathrm{x})$ & Ordinate of the roughness profile \\
\hline $\mathrm{F}$ & Applied force \\
\hline $\mathrm{t}$ & Test time \\
\hline$\sigma$ & Engineering stress \\
\hline $\mathrm{A}_{0}$ & Cross section area of input and output bars (SHPB apparatus) \\
\hline $\mathrm{A}_{\mathrm{s}}$ & Cross section area of volcanic sand samples \\
\hline $\mathrm{E}_{0}$ & Modulus of elasticity of input and output bars (SHPB apparatus) \\
\hline $\mathrm{c}_{0}$ & Elastic wave propagation velocity of input and output bars (SHPB apparatus) \\
\hline$\varepsilon_{\mathrm{i}(\mathrm{t})}$ & Incident strain history measured on the input bar of the SHPB apparatus \\
\hline$\varepsilon_{\mathrm{r}(\mathrm{t})}$ & Reflected strain history measured on the input bar of the SHPB apparatus \\
\hline$\varepsilon_{\mathrm{t}(\mathrm{t})}$ & Transmitted strain history measured on the output bar of the SHPB apparatus \\
\hline
\end{tabular}


Table 2 Summary of the experiments conducted in this study

\begin{tabular}{|c|c|c|c|c|c|c|c|c|}
\hline Consolidation & Confinement & $\mathrm{m}(\mathrm{g})$ & e $(-)$ & $\mathrm{L}(\mathrm{mm})$ & $\mathrm{D}(\mathrm{mm})$ & Average SR $\left[\mathrm{s}^{-1}\right]$ & Repetitions & Type \\
\hline Loose & Rigid & 2.2 & 1.77 & 6.8 & 20 & $5 \mathrm{E}-04$ & 5 & Compression \\
\hline Loose & Deformable & 2.2 & 1.77 & 6.8 & 20 & $5 \mathrm{E}-04$ & 3 & Compression \\
\hline Loose & Rigid & 2.2 & 1.77 & 6.8 & 20 & 1498 & 5 & Compression \\
\hline Loose & Deformable & 2.2 & 1.77 & 6.8 & 20 & 1510 & 5 & Compression \\
\hline Loose & Rigid & 2.2 & 1.77 & 6.8 & 20 & - & 4 & Wear \\
\hline Loose & Deformable & 2.2 & 1.77 & 6.8 & 20 & - & 4 & Wear \\
\hline Dense & Rigid & 2.9 & 1.11 & 6.8 & 20 & $5 \mathrm{E}-04$ & 7 & Compression \\
\hline Dense & Rigid & 2.9 & 1.11 & 6.8 & 20 & 1421 & 5 & Compression \\
\hline Dense & Rigid & 2.9 & 1.11 & 6.8 & 20 & - & 4 & Wear \\
\hline Dense & Deformable & 2.9 & 1.11 & 6.8 & 20 & - & 4 & Wear \\
\hline
\end{tabular}

subsequently photographed together with a calibration object. The Images were then converted to greyscale and then to binary black and white images by selecting an appropriate threshold. The areas of individual particles were evaluated and then converted to diameters of equivalent spherical particles. The chart in Fig. 1 illustrates the cumulative distribution of the computed sizes.

The granular structure of the volcanic sand was examined by means of a Carl Zeiss Evo LS15 Environmental Scanning Electron Microscope, equipped with a range of imaging detectors. The micrographs in Fig. 2 confirm a discretely wide distribution of sizes and illustrate the morphology of the material, characterised by a sub-angular shape and middle-low sphericity [2]. Etnean volcanic ashes are characterized by the presence of abundant vesicles (Fig. 2b, c) providing the grains with inherent porosity. These are small, generally spherical cavities generated in the magmatic material by the expansion of gases and steam prior to the complete solidification of the material. Their shape can occasionally assume a more complex geometry due to coalescence of multiple vesicles (Fig. 2c). The materials present in the volcanic ashes are representative of the lava melt as quenched right after the eruptive burst. Figure $2 d$ shows the partially vitreous nature of volcanic sand. This is caused by the very rapid cooling lava undergoes preventing its minerals to rearrange in a crystalline structure.

The mechanical response of a specific granular material is strongly dependent on its initial consolidation state and on the confinement used as the lateral constraint. The former is quantified using one of two equivalent parameters, the void ratio $e$ and the porosity $\eta$ (Table 1 ). The void ratio $e$ is defined as the ratio between the volume of voids $V_{v}$ and the volume of solids $V_{s}$ within the sample.

$e=\frac{V_{v}}{V_{s}}$

Whilst the porosity $\eta$, widely used in solid mechanics, is defined as the ratio between the volume of voids $V_{v}$ and the total volume $V_{t}$ of the specimen under consideration.
$\eta=\frac{V_{v}}{V_{t}}=1-\frac{V_{s}}{V_{t}}$

The two parameters are linked by the following equations.

$\eta=\frac{e}{1+e}$

$e=\frac{\eta}{1-\eta}$

and are univocally defined once the volume $V_{t}$ of the container, the density $\rho_{s}$ of the sand grains and their total mass are known $\left(\rho_{s}=2.86 \mathrm{~g} / \mathrm{cm}^{3}\right.$ for Etnean volcanic sand grains).

Two procedures for the preparation of loose and dense volcanic sand assemblies were developed in order to obtain specimens of consistent void ratio $e$.

The volume of the specimens was determined a priori via numerical evaluation of the representative volume element of the volcanic sand under consideration. Different consolidation states were obtained by keeping the geometry of specimens constant and by varying the mass of sand constituting the specimen. Loose sand assemblies (Table 2) were prepared by weighing the required mass of sand $m_{l}$ using a precision scale ${ }^{1}$ and by pouring it into the confinement using a small funnel, avoiding any contact between the funnel and the lateral walls of the container. Dense sand assemblies (Table 2) were also produced by weighing the required mass of sand $m_{d}$ using a precision scale. The amount of sand was divided in three portions of equal mass. The same procedure was then repeated for each of the three portions:

- The sand was poured into the confinement using a funnel.

- The free surface of the sand assembly was levelled tapping the container five times on four diametrically opposite points along the cylindrical container.

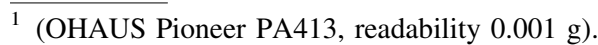


Fig. 3 Geometry and dimensions of the confinements used in this study: a rigid confinement for near-uniaxial strain experiments and b deformable confinement for near-uniaxial stress experiments

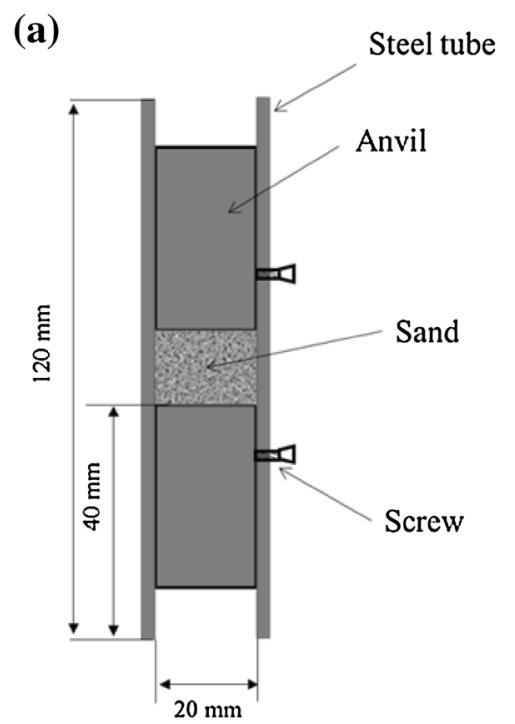

(b)

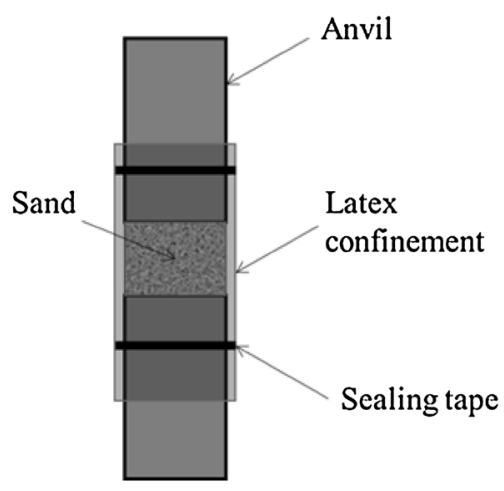

- The volcanic ashes were compacted by dropping a weight of fixed mass $\left(m_{w}=240 \mathrm{~g}\right)$ ten times from a height of $100 \mathrm{~mm}$.

Table 2 summarises masses, void ratios and testing conditions of all experiments conducted in the present study. It is worth mentioning that the values of void ratios obtained for volcanic sand are significantly higher than the usual void ratios achievable for silica sand assemblies [27]. This is due to the inherent porosity determined by the presence of numerous vesicles in the material.

Two types of confinement, exerting different confining pressures on the volcanic sand samples during compression, were used. High confining pressures were exercised using stainless steel confinements of thickness equal to $5 \mathrm{~mm}$. This containment allowed near-uniaxial strain conditions to be maintained throughout the experiments [28]. Low confining pressures were applied using highly deformable latex confinements, opposing negligible resistance to the radial expansion of sand samples during compression. This containment ensured the achievement of near-uniaxial stress conditions [28]. Figure 3 illustrates geometry and dimensions of the confinements used.

\section{Experimental Methods}

\section{Quasi Static Tests}

Compression tests on volcanic sand samples were conducted at low strain rate by means of a screw-driven universal testing machine. ${ }^{2}$ The volcanic sand grains constituting the samples were confined using the cylindrical containers detailed in Fig. 3. The applied load was

\footnotetext{
${ }^{2}$ Zwick/Roell Z250 materials testing machine.
}

recorded by a resistive load cell ${ }^{3}$ while a non-contact laser extensometer was employed to record the compressive strains.

\section{High Strain Rate Tests}

The mechanical response of Etnean volcanic sand at strain rates representative of impact loading was assessed by conducting a series of laboratory experiments on the Split Hopkinson Pressure Bar apparatus (Fig. 4a). During the experiments, the striker, accelerated by a compressed air piston system, collides with the input bar thus generating a compressive stress wave which propagates along the input bar until reaching the sample, sandwiched between the two bars. Because of the mechanical impedance mismatch between the specimen and the bars the incident pulse is partially reflected back to the input bar and partially transmitted through the output bar. The strain rate, strain and stress histories in the specimen can therefore be determined from the recorded strain gauge signals according to one dimensional wave analysis as follows [29]:

$$
\begin{aligned}
& \dot{\varepsilon}(t)=\frac{c_{0}}{l}\left[\varepsilon_{i}(t)-\varepsilon_{r}(t)-\varepsilon_{t}(t)\right] \\
& \varepsilon=\int_{0}^{T} \dot{\varepsilon}(t) d t=\frac{c_{0}}{l} \int_{0}^{T}\left[\varepsilon_{i}(t)-\varepsilon_{r}(t)-\varepsilon_{t}(t)\right] d t \\
& \sigma(t)=\frac{A_{0}}{2 A_{s}} E_{0}\left[\varepsilon_{i}(t)+\varepsilon_{r}(t)+\varepsilon_{t}(t)\right]
\end{aligned}
$$

where $l$ is the length of the sample, while $\varepsilon_{\mathrm{i}}(\mathrm{t}), \varepsilon_{\mathrm{r}}(\mathrm{t})$ and $\varepsilon_{\mathrm{t}}(\mathrm{t})$ are the incident, reflected and transmitted strain histories respectively. Furthermore, $A_{0}$ and $A_{s}$ are the cross section areas of the bars and specimen; $E_{0}$ and $c_{0}$ are the

\footnotetext{
${ }^{3}$ Zwick Xforce P20 resistive load cell.
} 
Fig. 4 Split Pressure Hopkison Bar apparatus: a experimental setup for the determination of mechanical properties at high strain rate; $\mathbf{b}$ experimental setup used as loading device during dynamic wear tests (a)



(b)

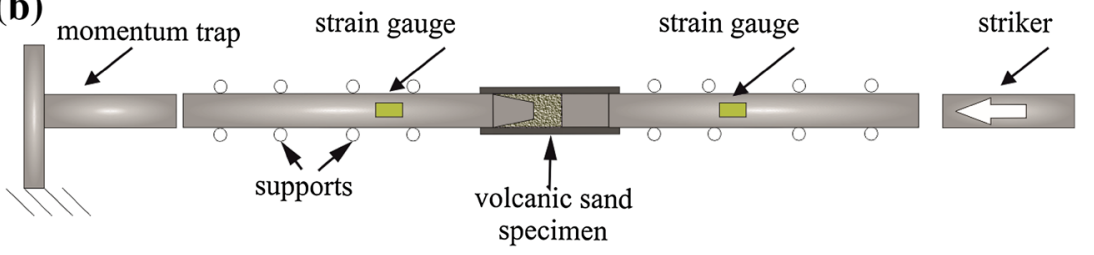

Young's modulus and the elastic wave propagation velocity of the material of the bars.

The true stress-true strain relationship is generally obtained synchronizing the analysis of images of the deforming material with the applied loading history. However the experiments presented in this study were conducted enclosing volcanic sand samples in either metallic or non-transparent confinements. For this reason the mechanical response of Etnean sand was expressed in terms of engineering stresses and strains, under the assumption of uniform distribution of stresses and strains within the samples.

The measurement of the high strain rate response of granular media poses further challenges, particularly in the case of inherently porous particles. Granular materials are characterized by a low stress wave propagation speed, requiring relatively long times to achieve dynamic equilibrium. These times are typically reduced by minimizing the specimen length, which is limited by the smallest representative volume element of the material [26]. In addition, unlike fully dense solid materials, where the specimens can be of lower diameter, the cross section of compression specimens of granular material is defined by the diameter of the loading bars. Consequently, the magnitude as well as duration of the stress pulses required to compress these relatively large samples and to evaluate the mechanical response of the given granular material up to maximum consolidation strains need to be increased substantially. These difficulties were overcome by using a LSHPB apparatus featuring striker and loading bars of considerable length. The device used in the experiments comprised of an impactor and instrumented input and output bars made of Ti-6Al-4 V, of length and diameter equal to $2.7 \mathrm{~m}$ and $20 \mathrm{~mm}$ respectively. Both bars were supported using low-friction polymeric circular bearings in order to avoid any lateral movement and buckling during loading. Because the length of the projectile determines the duration of the incident stress pulse [29], the use of this setup allowed for longer loading durations and, in turn, higher strains. Cardboard shims $\left(436 \mathrm{~g} / \mathrm{m}^{2}\right)$ of $1 \mathrm{~mm}$ thickness were used to reduce the high-frequency content in the signal, Pochhammer-Chree oscillations and to facilitate dynamic equilibrium.

\section{Dynamic Wear Tests}

An additional series of experiments was carried out using the LSHPB apparatus as a loading device with the purpose of evaluating the effect of volcanic sand impingement on cylindrical and wedged anvils made of Ti-6Al-4 V alloy (Fig. 4b). During these experiments the stress pulse, generated by the impact of the striker bar, propagates along the input bar and is transmitted to the volcanic sand sample causing its grains to impinge on an anvil of given geometry placed between the specimen and the output bar. The tests were conducted using the same striker bar employed for the high rate compression experiments, generating pulses of magnitude approximately equal to $40 \mathrm{kN}$ and duration of about $1.1 \mathrm{~ms}$. The anvils were replaced after every test and their surface, eroded by the impingement of volcanic

Table 3 Summary of dynamic wear experiments conducted in this study

\begin{tabular}{llll}
\hline Anvil type & Confinement type & Consolidation & Repetitions \\
\hline Flat & Rigid & Dense & 2 \\
Flat & Deformable & Dense & 2 \\
Flat & Rigid & Loose & 2 \\
Flat & Deformable & Loose & 2 \\
$45^{\circ}$ wedge anvils & Rigid & Dense & 2 \\
$45^{\circ}$ wedge anvils & Deformable & Dense & 2 \\
$30^{\circ}$ wedge anvils & Rigid & Dense & 2 \\
$30^{\circ}$ wedge anvils & Deformable & Dense & 2 \\
\hline
\end{tabular}


Fig. 5 Geometry of the anvils used during dynamic wear tests on Ti-6Al-4 V alloy impacted by Etnean volcanic ashes. Anvils of conical shape were not used because of the unpractical optical roughness analysis of surfaces with pronounced curvature
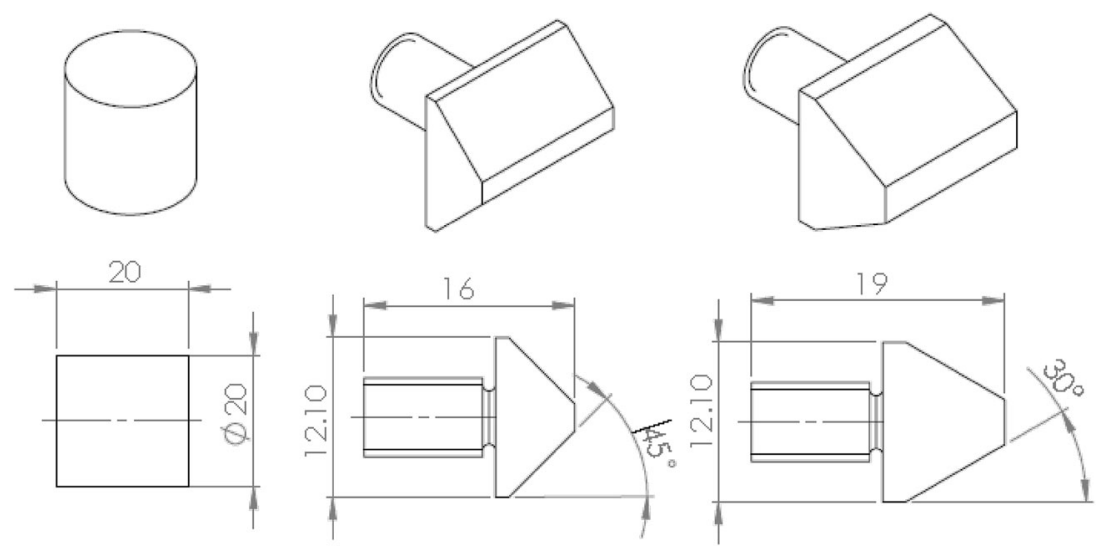

particulate, examined by means of a three dimensional optical profilometer. ${ }^{4}$ The surface texture and roughness of unused flat and wedged anvils were also examined and the corresponding measurements used as the basis for comparison with the surfaces eroded by the volcanic ashes. The dynamic wear tests were conducted in eight different configurations, utilizing steel and latex sand confinements and anvils of different geometries. Table 3 summarizes the wear tests carried out. The geometry of the anvils employed for the latter experiments is shown in Fig. 5.

The roughness analysis was conducted in compliance with DIN EN ISO 4288 standards in order to allow for the appropriate separation of the roughness profile from the waviness profile. Measurements of the asperity profiles were taken along six linear sections for each of the surfaces investigated, using a $3 \mathrm{D}$ profilometer ${ }^{4}$ equipped with a $20 \times$ magnification objective lens. The relevant quantities were then averaged in order to be representative of the whole area. Each impingement test was repeated two times for each of the test configurations reported in Table 3.

The following parameters were measured and exported:

$R_{a}=\frac{1}{l_{r}} \int_{o}^{l_{r}}|z(x)| d x$

$R_{q}=\sqrt{\frac{1}{l_{r}} \int_{0}^{l_{r}}\left|z^{2}(x)\right| d x}$

$R_{t}=z(x)_{\max }-z(x)_{\min }$

where $R_{a}$ is the roughness average, $R_{q}$ is the root mean square of the roughness profile ordinates, $R_{t}$ is the maximum peak to valley height of the roughness profile, $l_{r}$ is the length of the roughness profile examined and $z(x)$ is the generic roughness profile ordinate. In addition, each of the indented anvils was inspected also at lower magnifications using 5 and $10 \times$ magnification objective lenses in order to

\footnotetext{
${ }^{4}$ Alicona Infinite Focus 3D profilometer.
}

visualize the effects caused by the impact of volcanic particles at different scales.

\section{Experimental Results}

\section{Quasi Static and High Strain Rate Results}

This section presents the stress-strain relationship measured during experiments on volcanic ashes in order to assess the strain rate sensitivity of the material. Experiments conducted at each strain rate, confinement and consolidation conditions were repeated a number of times in order to evaluate the variability in material response (Table 2).

Representative nominal stress-strain curves, recorded during quasi static experiments are presented in Fig. 6. More specifically, Fig. 6a illustrates the effect of initial consolidation on the mechanical response of volcanic sand enclosed in a rigid confinement. The response of dense Etnean sand is characterized, similarly to other types of sand, by clearly distinguishable aspects of the macroscopic stress-strain relationship [28, 30]. At small strains, up to the engineering strains in the region of about $2 \%$, the intergranular forces in the assembly do not exceed the static friction acting between individual particles. The grains deform without any substantial sliding thus reflecting an apparent elastic portion in the stress strain curve. Higher loads cause the particles to roll and slide, rearranging themselves within the intergranular void therefore achieving a denser state. The relative movement between the grains becomes more and more difficult until lock-up conditions occur at strains ranging between 20 and $25 \%$. Further increments of the load cause particle crushing and a progressive reduction of the void ratio leading to a stiffer response.

The loose volcanic sand assemblies are more compliant. The initial apparent elastic phase is not distinguishable and the rearrangement of grains starts immediately when 
compression load is applied. Lock-up conditions occur at strains in the region of $30-35 \%$, corresponding to engineering stresses in the region of $20 \mathrm{MPa}$.

Figure $6 \mathrm{~b}$ shows the effect of the stiffness of the lateral confinement on the response of loose Etnean sand. The mechanical behaviour of samples enclosed in metallic and latex confinements is substantially identical up to engineering strains in the region of $6 \%$. Further loading causes the latex confinement to expand radially; consequently, the stress versus strain characteristic plateaus at a stress of about 1.3 MPa up to engineering strains of approximately $30 \%$. Further compression induces the compaction of the volcanic sand grains trapped between the anvils. These start to crush until achieving, at strains in the region of $50 \%$, a stiffness comparable to the one obtained after the occurrence of lock-up conditions when using rigid confinements.

The validity of the high strain rate tests was verified by checking that the dynamic force equilibrium conditions were achieved during the experiments conducted on the Long-SHPB apparatus. Figure 7 presents time histories of
Fig. 7 Dynamic equilibrium conditions during SHPB experiments on a dense volcanic sand sample in rigid confinement, b loose volcanic sand sample in rigid confinement and $\mathbf{c}$ loose volcanic sand sample in latex confinement

the forces measured from the input and output bars for all categories of samples under investigation. Strain rate histories are displayed on the same charts. For dense volcanic sand samples enclosed in rigid confinement (Fig. 7a) equilibrium conditions were achieved at a time of approximately $87 \mu \mathrm{s}$, corresponding to engineering strains in the region of $13 \%$. Force equilibrium conditions for loose sand samples enclosed in a rigid confinement (Fig. 7b) were attained at a time of $96 \mu$ s corresponding to a nominal compressive strain of approximately $12 \%$. Validity conditions for loose Etnean ashes enclosed in a latex confinement were obtained at a test time of about $81 \mu$ s equivalent to engineering strains of approximately $11 \%$. The dynamic stress-strain relationship is considered valid for strains beyond the above reported values, i.e. when the strain rate histories became approximately constant for all testing configurations.
Fig. 6 Mechanical response of Etnean volcanic ashes at quasi static strain rate: a effect of the initial compaction on samples enclosed in rigid confinements; b effect of the type of container on the response of loose sand
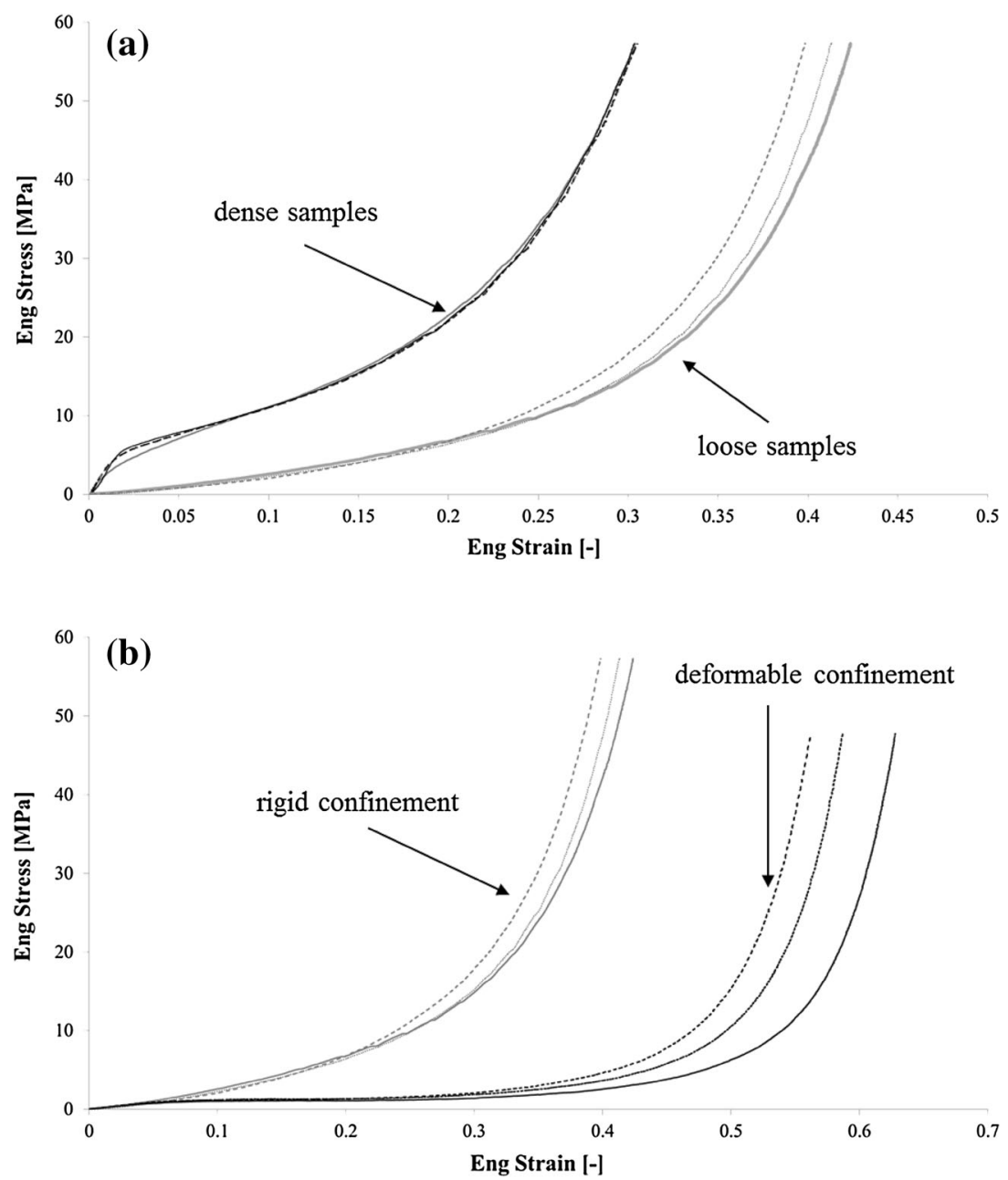

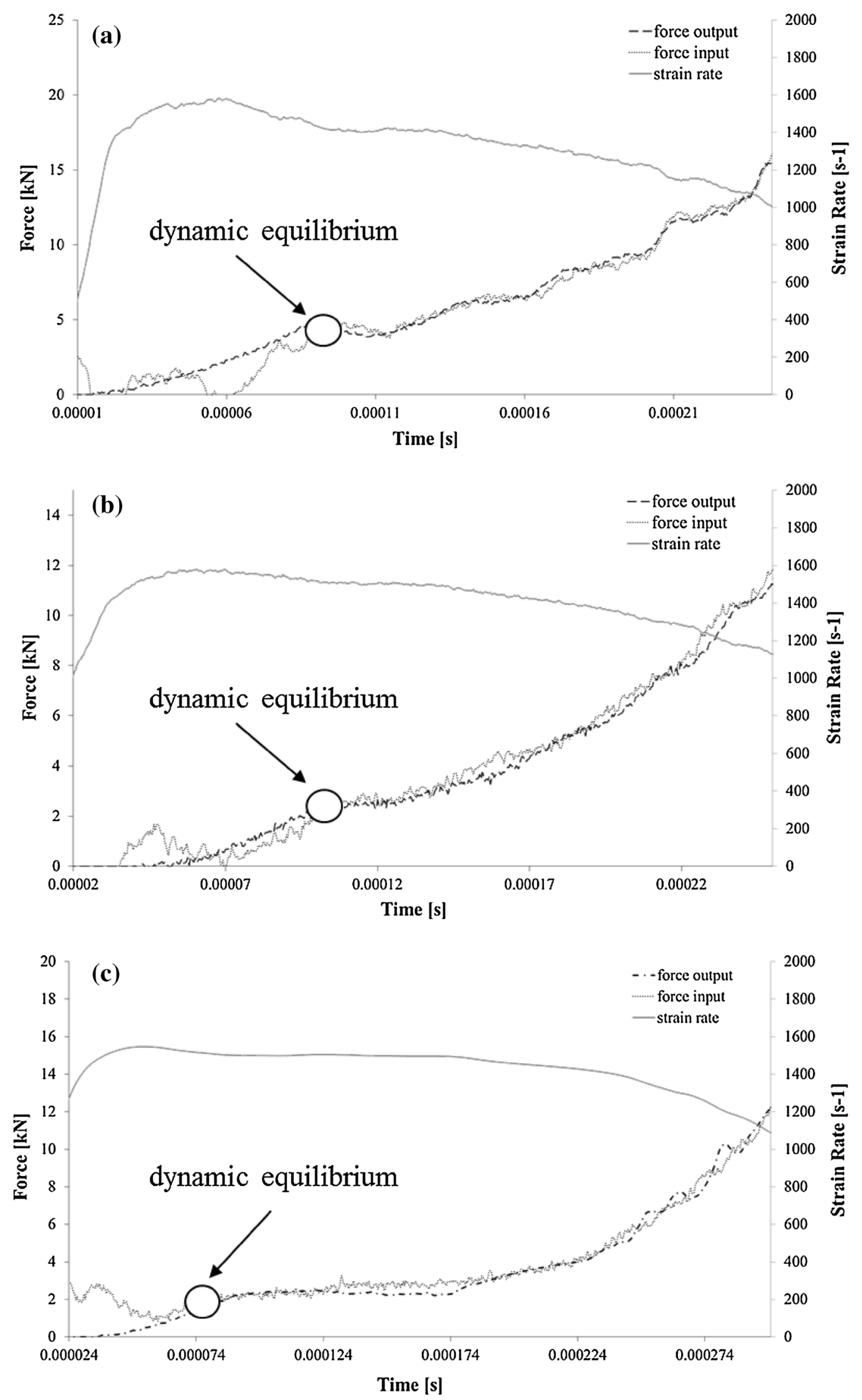
The deformation mechanisms of granular materials to which the origins of their macroscopic strain rate sensitivity is attributed, are, primarily, the particle crushing, particle sliding and grains rearrangement within the sample volume. Although particle crushing is a time consuming process the macroscopic response of sand assemblies may not be sensitive to particle breakage due to the small dimensions of grains constituting the sands typically investigated using the SHPB apparatus [28]. This is confirmed by the results presented in Fig. 8a showing that the response of dense Etnean ashes confined in steel containers is not noticeably rate sensitive. Conversely, Fig. 8b shows the significant rate dependence of loose Etnean sand samples tested enclosed in near-rigid confinements. This is most probably due to the more significant influence of sliding and rearrangement mechanisms when loading loose sand rather than dense sand. During high rate experiments particles have a dramatically reduced amount of time to reorganize, yielding a stronger response. Similarly the mechanical response of loose volcanic ashes in latex confinements exhibits a noticeable rate dependence (Fig. 8c) with the plateau region of the mechanical characteristic, at stress values of approximately 1.3 MPa when loaded quasi statically, increasing to $7 \mathrm{MPa}$ when loaded dynamically.

\section{Dynamic Wear Tests Results}

This section describes the effect of the impingement of volcanic ashes on the surface of Ti-6Al-4 V alloy anvils of various geometries (Fig. 5) enclosed in rigid and deformable confinements. The surface deterioration caused by the impact loading of Etnean sand is analyzed both by assessing the erosion wear mechanism and by quantifying the increment in the surface roughness with respect to the surface texture of unused anvils.

When flat anvils are impacted by volcanic particles samples enclosed in metallic confinements the boundary conditions imposed by the container do not allow for any relevant radial movement of the grains. The particles impact the surface of the titanium anvils in a substantially perpendicular manner. Consequently, the erosion wear mechanism observed for this class of experiments was mainly indentation (Fig. 9). However, during experiments conducted using deformable confinements the particles are allowed to move perpendicularly with respect to the loading direction. The effect of this radial motion was particularly evident during the inspection of the eroded surfaces. The erosion wear mechanism appeared to be dominated by indentation on the central portion of the anvils and by approximately axisymmetric ploughing on their peripheral portion (Fig. 10).

Table 4 summarises the roughness parameters $R_{a}, R_{q}$ and $R_{t}$ pertinent to all dynamic wear experiments carried out impacting dense and loose samples on flat anvils. All values were determined according to the procedure detailed in Sect. 3.3. The corresponding parameters relevant to the surface texture of unused anvils are given in Table 4A.

When steel specimen confinements were used, the collision of consolidated volcanic ashes caused a measurable increment of the surface irregularity with respect to the reference surface conditions. The average roughness $R_{a}$ rose from approximately 290 to $331 \mathrm{~nm}$, while the parameter $R_{q}$ rose from 361 to $442 \mathrm{~nm}$ (Table 4B). Conversely, when loose volcanic grains were impinged at equal dynamic loading conditions, the values of these two parameters remained substantially unaffected, despite the sizable increase of the maximum peak to valley height of the roughness profile (Table 4C). This is thought to be due to the dissipation of the portion of energy responsible for the rearrangement of the particles during compression loading.

Similarly, when latex confinements were used, the impacted surfaces, etched by radial grooves, showed a significant increment of their irregularity with respect to as machined surface conditions. The measured average roughness $R_{a}$ increased from 290.4 to $424.4 \mathrm{~nm}$ when using dense samples and from 290.4 to $425 \mathrm{~nm}$ when using loose samples. The root mean square of the roughness profile $R_{q}$ increased from 360.6 to $586.2 \mathrm{~nm}$ and $567.3 \mathrm{~nm}$ when using dense and loose samples respectively (Table 4D, E).

When volcanic ashes collide with wedged anvils a component of their velocity is parallel to the surface of the wedges. The erosion wear mechanism observed for this category of experiments comprises of an initial indentation followed by an evident abrasion of the surface (Fig. 11). In the case of steel confinement the relative movement between the particles and the surface indented is restricted by the boundary conditions imposed by the metallic cylinders encasing the samples. Indentation and subsequent abrasion grooves appeared to be deeper on $45^{\circ}$ wedged anvils, with longer scratches observed on $30^{\circ}$ wedged anvils. In contrast, deformable confinements allow the particles larger displacements and the whole sand assembly to expand radially. The depth and length of the resulting grooves depends on the combination of the initial angle of impact and on the pressure exerted by the particles during the radial expansion of the latex containers. The surface profile analysis conducted on $30^{\circ}$ wedged anvils revealed an abundant number of grooves produced by the abrasion of the volcanic particles (Fig. 12b). However these appeared to be shallower in comparison to the grooves produced on $45^{\circ}$ wedged anvils subjected to the same loading conditions (Fig. 12a). This is explained by the variation of the pressure exercised by the volcanic sand as a result of the expansion of stretchable confinements. When 
Fig. 8 Comparison of the mechanical response of volcanic ashes at high and low strain rates. Rate dependence of a dense samples enclosed in rigid confinements, b loose assemblies restrained in rigid confinements and $\mathbf{c}$ loose samples enclosed in latex confinements
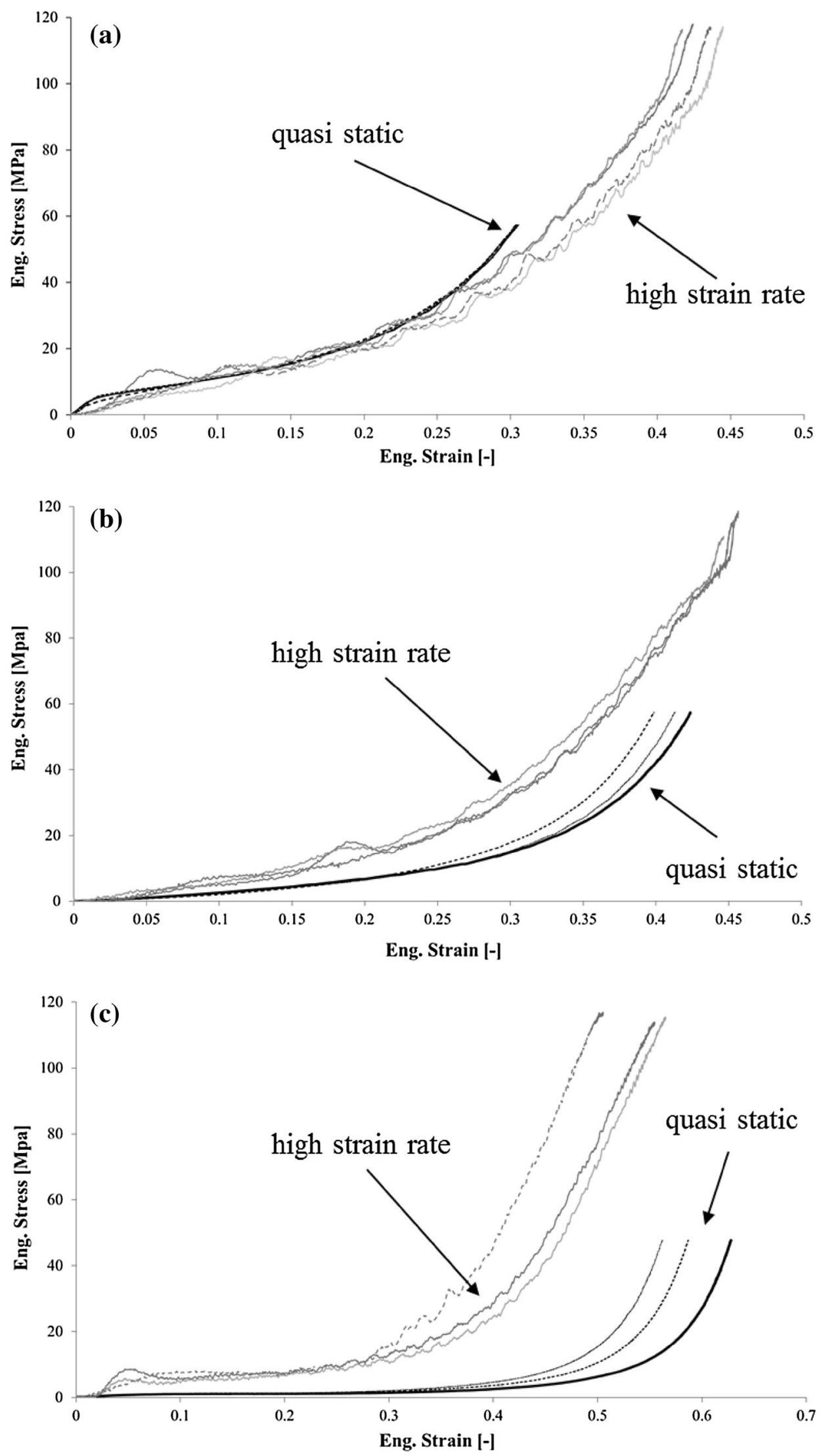



Fig. 9 Erosion caused by the impingement of Etnean volcanic ashes on flat anvils. Dense samples in rigid confinement
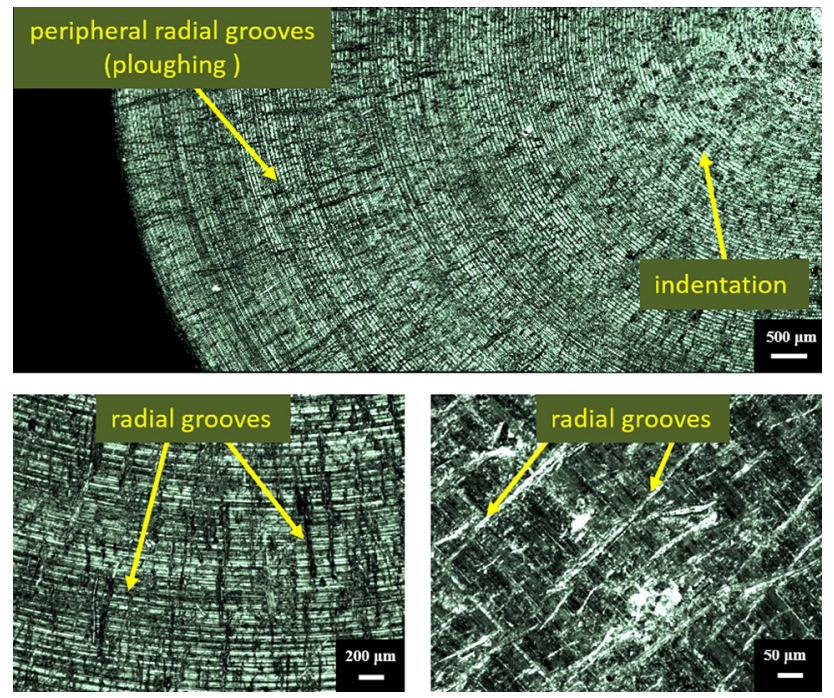

Fig. 10 Erosion caused by the impingement of Etnean volcanic ashes on flat anvils. Dense samples in deformable confinement

the angle of impact is low the pressure applied by the particles on the titanium surfaces decreases substantially during the deformation of the samples; whereas, at higher angles of impact, the particles keep on applying pressure while sliding.

Table 5 summarizes the dynamic wear tests results obtained on wedged anvils impinged by dense volcanic sand samples. The roughness parameters corresponding to the surface of unused wedge anvils are reported in Table 5A).

The increment of roughness caused by the abrasion of Etnean ashes is prominent in the case of $45^{\circ}$ wedged anvils. When steel confinements were used the average roughness $R_{a}$ increased from a value of approximately $313 \mathrm{~nm}$, corresponding to unused anvils, to $447 \mathrm{~nm}$. The root mean square $R_{q}$ of the roughness profile ordinates raised from 381 to $909 \mathrm{~nm}$ (Table 5B). The effects of the
Table 4 Summary of surface roughness measurements for all dynamic wear tests conducted on flat anvils

\begin{tabular}{lcc}
\hline (A) Reference unused anvil & \\
$\mathrm{R}_{\mathrm{a}}$ & 290.4376 & $\mathrm{~nm}$ \\
$\mathrm{R}_{\mathrm{q}}$ & 360.6316333 & $\mathrm{~nm}$ \\
$\mathrm{R}_{\mathrm{t}}$ & 2.6559 & $\mu \mathrm{m}$ \\
$(\mathrm{B})$ Dense samples, rigid confinement & \\
$\mathrm{R}_{\mathrm{a}}$ & 330.8908417 & $\mathrm{~nm}$ \\
$\mathrm{R}_{\mathrm{q}}$ & 442.89795 & $\mathrm{~nm}$ \\
$\mathrm{R}_{\mathrm{t}}$ & 6.1402 & $\mu \mathrm{m}$ \\
$(\mathrm{C})$ Loose samples, rigid confinement & \\
$\mathrm{R}_{\mathrm{a}}$ & 279.76845 & $\mathrm{~nm}$ \\
$\mathrm{R}_{\mathrm{q}}$ & 373.9176 & $\mathrm{~nm}$ \\
$\mathrm{R}_{\mathrm{t}}$ & 5.3264 & $\mu \mathrm{m}$ \\
$(\mathrm{D})$ Dense samples, deformable confinement & \\
$\mathrm{R}_{\mathrm{a}}$ & 424.4134333 & $\mathrm{~nm}$ \\
$\mathrm{R}_{\mathrm{q}}$ & 586.1568917 & $\mathrm{~nm}$ \\
$\mathrm{R}_{\mathrm{t}}$ & 7.0601 & $\mu \mathrm{m}$ \\
$(\mathrm{E})$ Loose samples, deformable confinement & \\
$\mathrm{R}_{\mathrm{a}}$ & 424.9736 & $\mathrm{~nm}$ \\
$\mathrm{R}_{\mathrm{q}}$ & 567.25655 & $\mathrm{~nm}$ \\
$\mathrm{R}_{\mathrm{t}}$ & 3.5941 & $\mu \mathrm{m}$ \\
\hline
\end{tabular}

erosion are even more evident in the case of latex confinements, as indicated by increments of the parameters $R_{a}$ and $R_{q}$ equal to 88 and $139 \%$ respectively (Table 5C).

Experiments conducted on $30^{\circ}$ wedged anvils showed results similar to the ones obtained using 45 degreed wedged anvils in the case of sand samples enclosed within rigid containments, with increments of the parameters $R_{a}$ and $R_{q}$, with respect to as machined conditions, equal to 99 and $125 \%$ respectively (Table 5D). Conversely, when anvils of the same geometry were impacted by sand samples enclosed in deformable confinements the resulting 
Fig. 11 Erosion caused by the impingement on wedged anvils of compacted Etnean volcanic ashes enclosed in rigid confinements: a $45^{\circ}$ wedged anvils; b $30^{\circ}$ wedged anvils
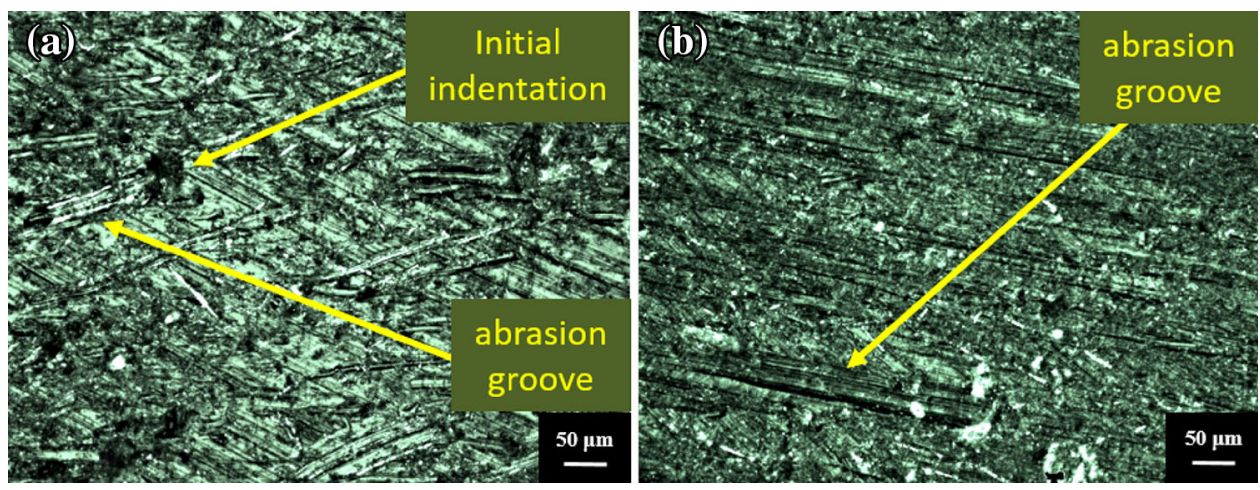

Fig. 12 Erosion caused by the impingement on wedged anvils of compacted Etnean volcanic ashes enclosed in deformable confinements: a $45^{\circ}$ wedged anvils; b $30^{\circ}$ wedged anvils
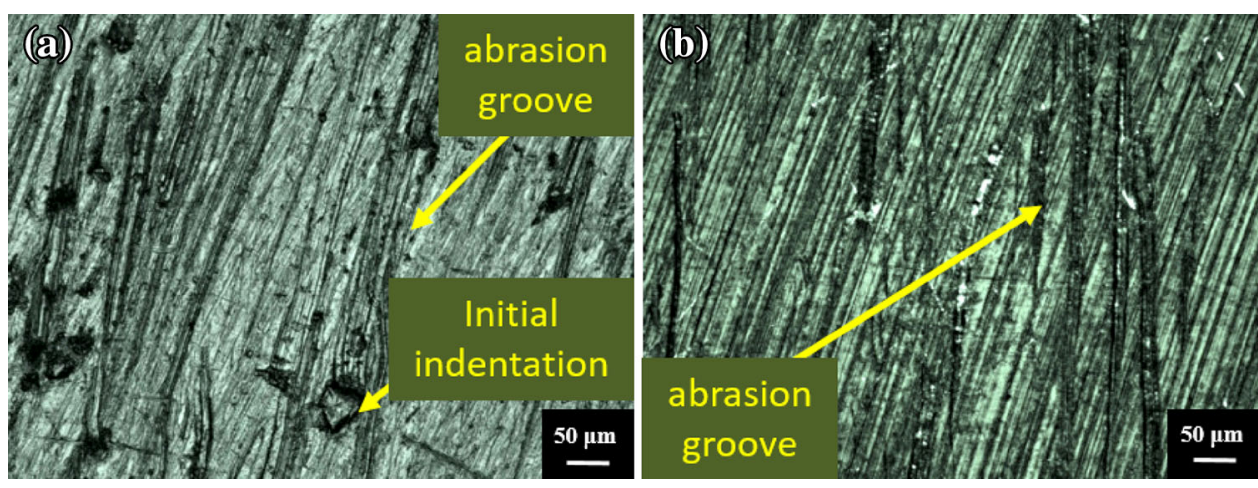

Table 5 Summary of surface roughness measurements for all dynamic wear tests conducted on wedged anvils (all samples were in a dense consolidation state)

(A) Wedged reference unused anvil

$\begin{array}{ll}\mathrm{R}_{\mathrm{a}} & 313.34935 \\ \mathrm{R}_{\mathrm{q}} & 388.4377167 \\ \mathrm{R}_{\mathrm{t}} & 2.3095\end{array}$

(B) $45^{\circ}$ anvils, rigid confinement

\begin{tabular}{lcc}
$\mathrm{R}_{\mathrm{a}}$ & 447.0999667 & $\mathrm{~nm}$ \\
$\mathrm{R}_{\mathrm{q}}$ & 908.9871917 & $\mathrm{~nm}$ \\
$\mathrm{R}_{\mathrm{t}}$ & 17.8666 & $\mu \mathrm{m}$ \\
$(\mathrm{C}) 45^{\circ}$ anvils, deformable confinement & \\
$\mathrm{R}_{\mathrm{a}}$ & 590.5389417 & $\mathrm{~nm}$ \\
$\mathrm{R}_{\mathrm{q}}$ & 929.2521083 & $\mathrm{~nm}$ \\
$\mathrm{R}_{\mathrm{t}}$ & 10.8672 & $\mu \mathrm{m}$ \\
$(\mathrm{D}) 30^{\circ}$ anvils, rigid confinement & \\
$\mathrm{R}_{\mathrm{a}}$ & 623.1832583 & $\mathrm{~nm}$ \\
$\mathrm{R}_{\mathrm{q}}$ & 874.3773833 & $\mathrm{~nm}$ \\
$\mathrm{R}_{\mathrm{t}}$ & 12.3783 & $\mu \mathrm{m}$ \\
$(\mathrm{E}) 30^{\circ}$ anvils, deformable confinement & \\
$\mathrm{R}_{\mathrm{a}}$ & 400.44095 & $\mathrm{~nm}$ \\
$\mathrm{R}_{\mathrm{q}}$ & 512.117725 & $\mathrm{~nm}$ \\
$\mathrm{R}_{\mathrm{t}}$ & 3.961 & $\mu \mathrm{m}$ \\
\hline
\end{tabular}

changes in roughness were relatively moderate (Table 5E), in agreement with the erosion wear mechanism analysis detailed above.

\section{Conclusions}

An experimental campaign was undertaken in order to characterize the response of Etnean volcanic sand at quasi static and high rate of strain and motivate the development of theoretical models for this material. The compressive response of samples of volcanic sand, assessed in their loose and dense initial consolidation states, was quantified by subjecting them to near-uniaxial strain and near-uniaxial stress loading at different rates of strain. The effects of lateral confinement, initial consolidation and strain rate were also evaluated. No similar set of data had been previously published mainly due to the difficulties associated with the dynamic experiments, which were overcome by using a bespoke Long Split Hopkinson Pressure Bar setup, by relying on load pulse shaping techniques and a priori determination of specimen dimensions by means of numerical analysis of the representative volume element.

An additional series of experiments were conducted to evaluate the erosion generated by the impact of volcanic particles on the surface of Ti-6Al-4 V alloy anvils. These were conducted by utilizing different anvil geometries in order to evaluate the influence of the incident angle upon the wear mechanisms. The effects of the initial sand consolidation and of the boundary conditions imposed by the lateral confinements on the erosion wear process were also assessed in order to simulate the response of volcanic sand at different depths of their natural deposits. 
The main conclusions of this study are:

- Etnean volcanic sand exhibits a noticeable strain rate sensitivity when tested in a loose consolidation state using both steel and latex confinement, indicating that the rate dependency of the material is mainly associated with particle sliding and grains rearrangement within the sample volume.

- The sand does not display any rate dependence when tested in a dense consolidation state using steel confinements, indicating that the rate sensitivity of the materials is not attributable to the particle breakage process, plausibly due to the small dimensions of the grains.

- The erosion wear mechanisms are influenced by both the angle of impact and the radial boundary conditions imposed by the confinements. They affect, simultaneously, the overall relative displacement and velocity between eroded surfaces and particles as well as the pressure applied by the particles during impact loading.

Acknowledgments The authors would like to thank Mr. Stuart Carter and Mr. Jeffrey Fullerton for their assistance with fixture preparation and experimental setup and Mrs. Karen Bamford for helping everyone stay focused.

\section{References}

1. D’Oriano C, Pompilio M, Bertagnini A, Ciani R, Pichavant M (2013) Effects of experimental reheating of natural basaltic ash at different temperatures and redox conditions. Contrib Mineral Petrol 165:863-883

2. Bandini V, Cascone E, Biondi G, Foti EF (2014) A laboratory investigation of the mechanical behaviour of a volcanic ash, 20th IMEKO TC4 International Symposium, Benevento (Italy)

3. Lautze NC, Taddeucci J, Andronico D, Cannata C, Tornetta L, Scarlato P, Houghton B, Lo MD (2012) Castro: SEM-based methods for the analysis of basaltic ash from weak explosive activity at Etna in 2006 and the 2007 eruptive crisis at Stromboli. Phys Chem Earth 45-46:113-127

4. Farooqui MY, Hou H, Li G, Machin N, Neville T, Pal A, Shrivastva C, Wang Y, Yang F, Yin C, Zhao J, Yang X (2009) Evaluating volcanic reservoirs. Oilfield Review 21(1):36-47

5. Magnani, P. 1; Re, E. 1; Senese, S. 1; Ori, G.G.2; Gily,A. 3;Baglioni,P. 4; Fumagalli, A. 1: Testing of Exomars EM Drill Tool in Mars Analogous Materials. Proceeding of the 11th Symposium on Advanced Space Technologies in Robotics and Automation, ASTRA 2011, 12-14 April 2011 ESA/ESTEC, ESTEC Conference Centre, Noordwijk

6. Yarali O, Sayer E (2011) The effect of mechanical rock properties and brittleness on drillability. Sci Res Essays 6:1077-1088

7. Mohamad ET, Saad R, Hamzah NNB, Ton SA, Liang M (2012) Assessment on abrasiveness of rock materials on the wear and tear of drilling tool. Electron J Geotechn Eng 17:91-100

8. Anderson CE, Behner CE, Tand Weiss S, Chocron RP Bigger (2010) Mine blast loading: experiments and simulations. Technical report Southwest Research Institute, Texas
9. Borg JP, Vogler TJ (2008) An experimental investigation of the high velocity projectile penetrating sand. In: Proceeding of the XIth International Congress And Exposition; Society for Experimental Mechanics Inc.,

10. An J (2010) Soil behaviour under blast loading. PhD thesis, University of Nebraska

11. Omidvar M, Iskander M, Bless S (2014) Response of granular media to rapid penetration. Int J Impact Eng 66:60-82

12. Iskander M, Bless S, Omidvar M (2015) Rapid Penetration Into Granular Media: Visualizing the Fundamental Physics of Rapid Earth Penetration. Elsevier, Amsterdam

13. EASA, report A-NPA 2012-2021, http://easa.europa.eu/docu ment-library/notices-of-proposed-amendments/npa-2012-21

14. Song W, Lavallée Y, Hess KU, Kueppers U, Cimarelli C, Dingwell DB (2016) Volcanic ash melting under conditions relevant to ash turbine interactions. Nature communications, Chicago, p 7

15. Shinozaki M, Roberts KA, Van de Goor B, Clyne TW (2013) Deposition of ingested volcanic sand on surfaces in the turbine of a small jet engine. Adv Eng Mater 15:986-994

16. Dunn MG (2012) Operation of gas turbine engines in an environment contaminated with volcanic ash. J Turbomach 134:1-18

17. Hamed A, Tabakoff W, Wenglarz R (2006) Erosion and deposition in turbomachinery. J Propul Power 22:350-360

18. Tilly GP (1969) Erosion caused by airborne particles. Wear 14:63-79

19. Tabakoff W, Kotwal R, Hamed A (1979) Erosion study of different materials affected by cool ash particles. Wear 52:161-173

20. Yasin A, Awwad MT, Hajjeh HR, Sahawneh EI (2012) Effect of volcanic tuff on the concrete compressive strength. Contemporary Engineering Sciences 5:295-306

21. Siddique R (2011) Effect of volcanic ash on the properties of cement paste and mortar, Resources, Conservation and Recycling, Vol. 56, p 66-70

22. Heap MJ, Lewis O, Meredith PG, Vinciguerra S (2007) Elastic and mechanical properties of Etna basalt. Geophys Res Abstr 9:06750

23. Barr AD, Clarke SD, Petkovski M, Tyas A, Rigby SE, Warren J, Kerr S (2016) Effects of strain rate and moisture content on the behaviour of sand under one-dimensional compression. Experimental Mechanics. doi:10.1007/s11340-016-0200-z

24. Martin BE, Chen W, Song B, Akers SA (2009) Moisture effects on the high strain-rate behavior of sand. Mech Mater 41(6):786-798

25. Suescun-Florez E, Kashuk S, Iskander M, Bless S (2015) Predicting the uniaxial compressive response of granular media over a wide range of strain rates using the strain energy density concept. J Dyn Behav Mater 1(3):330-346

26. De Cola F, Pellegrino A, Barbieri E, Penumadu D, Petrinic N (2016) Void ratio based representative volume element for modelling the high strain rate behaviour of granular materials. Int J Impact Eng 91:46-55

27. Kim FH, Penumadu D, Gregor J, Kardjilov N, Manke I (2012) High-resolution neutron and $X$-ray imaging of granular materials. J Geotech Geoenvironmental Eng 139(5):715-723

28. Omidvar M, Iskander M, Bless S (2012) Stress-strain behavior of sand at high strain rates. Int J Impact Eng 49:192-213

29. Kolsky H (1949) 'An investigation of the mechanical properties of materials at very high rates of loading', Proceedings of the Physical Society. Section B 62(11), 676

30. Hagerty MM, Hite DR, Ullrich CR, Hagerty DJ (1993) Onedimensional high-pressure compression of granular media. J Geotech Geoenvironmental Eng 119(1):1-18 